\title{
Summary Report of the Third International Congress of Person Centered Medicine and the First International Conference on Primary Care and Public Health, London, 29-31 October 2015
}

\author{
Sandra Van Dulmen and James Appleyard
}

\section{Day 1: Thursday October 29th}

It was a promising sunny autumnal day for the opening of the 3rd International Congress of Person Centred Medicine and the 1st International Conference of Primary Care and Public Health. Over two hundred and fifty participants were welcomed at the Sherfield Building of the Imperial College in London by our cheerful host, Professor Salman Rawaf and his professional team.

At the opening session, the President of Imperial College London, Professor Alice P. Gast, stressed the need for partnership, collaboration and cooperation in order to overcome health threats such as those stemming from the not yet affordable chronic diseases. Professor Azeem Majeed, Head of the Department of Primary Care and Public Health at Imperial College, reminded us of the importance of public health problems like the ageing population and obesity for which person centred primary care and public health are indispensable.

Professor Jim Appleyard, President of our International College of Person Centred Medicine, emphasized the relevance of strong primary care especially when delivered in a person centred way. He outlined the International College's aims involving the promotion of person centered healthcare with respect for the dignity and well-being of all people through person centred education and research.

Professor Derek Bell, the Director of the NIHR CLAHRC for Northwest London spoke of the relevance of compassionate healthcare, understandable information for patients and their participation in decision-making. Professor Helen Ward, Director of Education for the School of Public Health, referred to the science base of public health and asked for integrated solutions to solve prevalent healthcare problems.

In the Opening Plenary Session Doctor Ala Alwan, the WHO Regional Director for the Eastern Mediterranean, not being unable to attend personally, made a special video presentation. His message was that with the rise in the incidence of non-communicable diseases there needs to be a renewed focus on primary care with an emphasis on capacity building.

Professor Tawfik Khoja, the Director General, Executive Board of the Health Ministers' Council for Cooperation Council States, explained that the Gulf Cooperation Council (GCC) has been witnessing many healthcare challenges in the last few years. There are problems with sustainability, ageing, population growth and NCDs. The GCC spends less money on healthcare than other rich countries. According to Professor Khoja, the epidemiology of NCDs has to do with the fact that the current health system is a radar system; a patient appears, wants to be fixed, is sent home, and disappears from the radar. This radar system does not see the whole picture of life. Political commitment is needed as well as innovations in primary and patient centred care (e.g. school health). His message for the audience: Change illness into wellness!

Professor Salman Rawaf elaborated further on the value and effectiveness of primary care. With a reference to Barbara Starfield, he explained that primary care is about balancing health needs, services and technology because it supplies a person's first contact to longitudinal, comprehensive, person and family centred care with an orientation to the community.

During the coffee break, lively discussions continued and participants were able to view 37 poster presentations. They are available as Abstracts in this Journal together with Abstracts from presentations at the Plenary and Parallel Sessions. Their content can be considered along with the highlighted items of this Summary Report.

Each day following the Plenary Sessions participants could choose to attend one out of three parallel sessions covering a wide range of person centered care topics.

In the Great Hall, Professor Juan Mezzich's presentation on Conceptualizing and Measuring Person Centred Care was given by Professor Jim Appleyard and Professor Ihsan Salloum. This was followed by three papers from South Africa. Professor Bart Criel, spoke about patient centered care in African front line health services, constraints and opportunities. Dr Irwin Friedman talked of innovations that had transformed the South African health system and Dr Julia Moorman referred to Public health and Primary Care Education. In other parallel sessions, the overall discussion provided several relevant messages such as: keep humanity in clinical practice, value the doctor-patient relationship, 
electronic medical records are now too much focused on restraining costs and financial incentives and not focused enough on the doctor-patient relationship.

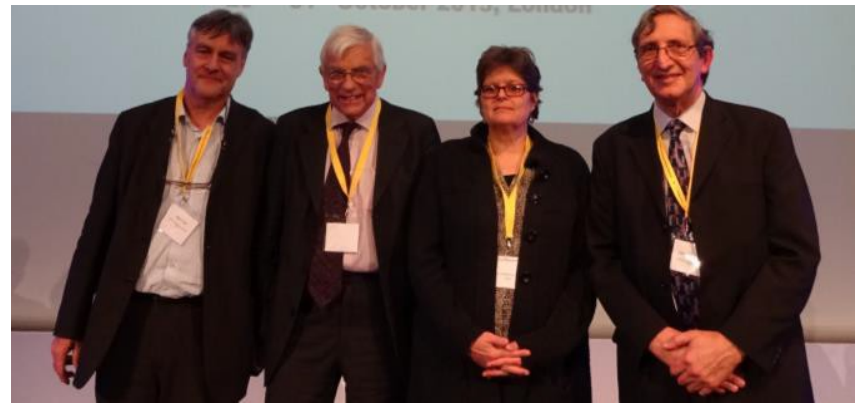

Professor Bart Criel, Professor J im Appleyard, Dr J ulia Moorman, and Dr Irwin Friedman

At the Plenary Session after lunch, Baroness Ilora Finlay, Professor of Palliative Medicine at Cardiff University, gave an inspiring talk about the humanity of end of life care, and Jon Snaedal, Professor of Geriatric Medicine in Iceland, spoke about the problems of Age and Ageism.

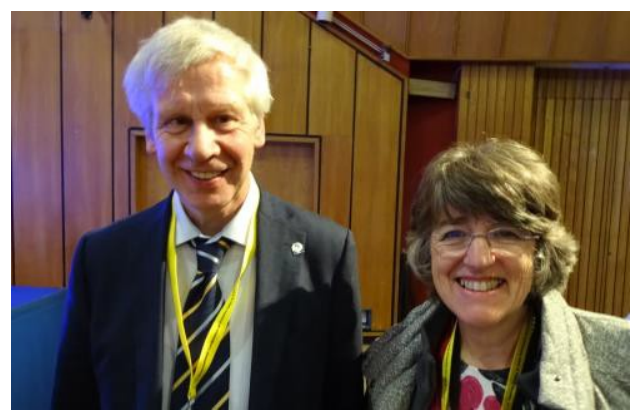

\section{Professor J on Snaedal and Baroness Professor Ilora Finlay}

During the afternoon parallel sessions of the first congress day, again different person centred topics were presented that, among others, stressed the need to pay attention to individual cardiovascular risk factors, to engaging individuals in their healthcare, to 'healthy living pharmacies', to inquire about a patient's individual health preferences, to the conceptualization of access to primary care, and to what matters most to older people with multiple chronic disease

During the plenary closing session for day 1, Professor Jim Appleyard drew attention to the draft of the London Declaration available on the Conference Website and invited all participants to provide their input and feedback for the Concluding Session on the following day.

At the evening of the first day of the conference, around 50 participants experienced a lovely and lively Conference 'Dinner on the Thames' with spectacular views of some familiar London Landmarks.

\section{Day 2: Friday October 30th}

The second day of the conference opened with a keynote lecture by Salman Rawaf about the need to scale up family physicians training in developing countries. He showed the positive effects on mortality of attracting more family physicians. He also made clear that the countries that are most in need of healthcare are the countries in war. These countries have a weak and low quality primary care with poor access and a shortage of human resources. Brazil did manage to get primary care funded in a relatively short period of time. Still, worldwide, there is a shortage of 10 million healthcare providers.

The plenary session continued with Professor Mitch Blair's lecture on early child years and mental health trajectories. He focused on building strong children and strong foundations to make that happen. He informed us that $70 \%$ of adult psychological problems can be ascribed to childhood adverse events and $10 \%$ of all children already have psychological problems. He worked in a school with children said to be 'mad, sad and bad', who show a catalogue of adverse events during childhood. The more of these events occur during childhood, the more ill health during adulthood. Healthy children need primary care, which provides holism, continuity and a system-based approach. The primary care team should identify risk factors at an early stage in life, provide good antenatal and postnatal care, nutrition and mental health and should help keep children at school.

Baroness Sheila Hollins, Professor Emeritus of the Psychiatry of Disability, gave a talk about how to engage and inform people with intellectual disabilities. She made 45 picture books about different situations for people who are not able to understand words because they are visually illiterate (www.booksbeyondwords.co.uk). If you want to 
understand a patient, she said, ask yourself what it is like to be this person at this time, in this place with these caregivers, and what it is like to be his/her caregiver? Make home visits to find out how and where patients live and listen to them! A narrative and person centred approach can make a huge difference.

After the formal lectures, Salman Rawaf invited a panel of experts to talk about how to change the system so that it could become more compassionate. The conclusion was that when you want to know the person behind the patient, you have to know yourself as a person (e.g. the person behind the healthcare provider).

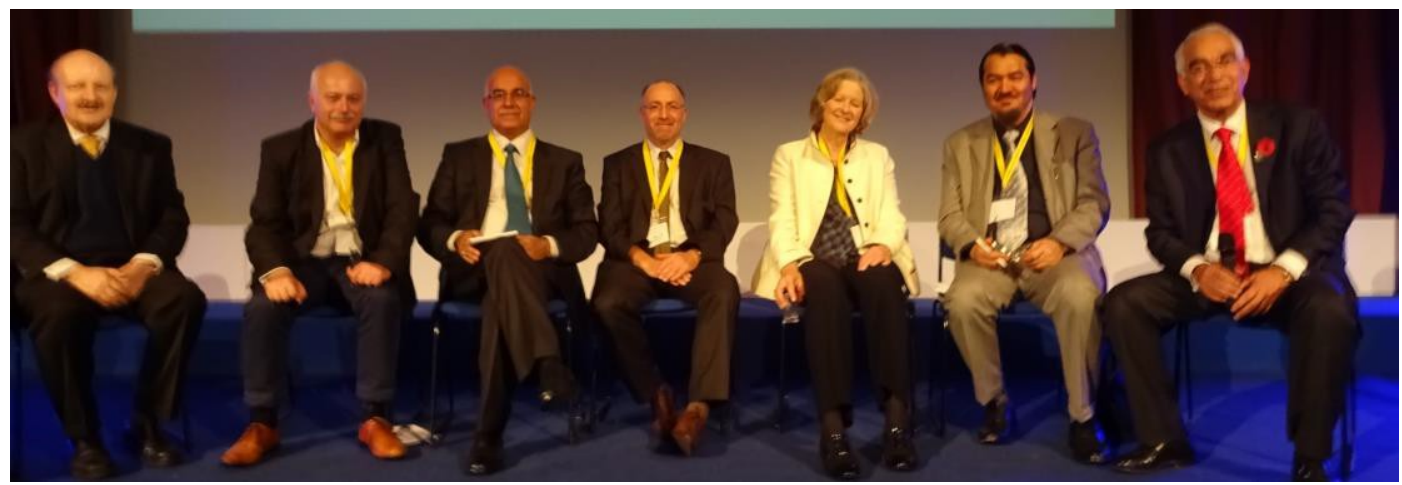

Prof Ihsan Salloum, Professor Michel Botbol, Professor Abdul Majeed Salmasi, Professor Mitch Blair, Professor the Baroness Sheila Hollins, Professor Tawfik Khoja, and Professor Salman Rawaf

During the morning parallel sessions, inspiring person centred talks were given, among others, about providing patient centred care for children and adolescents with chronic conditions (children want information about how to live with their disease, not only information about the disease itself; do healthcare providers have the skills to talk about these aspects?), subjective experiences of individuals receiving a diagnosis of Alzheimer's disease, and the 'windows method' to teach students consultation skills (e.g. what emotions has the patient evoked in me during this consultation?).

In the plenary session after lunch, Sir Al Aynsley Green, a children’s physician and paediatric endocrinologist, talked about the nurture of children and why this should be everyone's business. Still, children's needs are often subordinated in political priority to the needs of adults especially the elderly. He claimed that we need a paradigm shift in our attitude to children and young people and the services to support them. Three key words were explored to develop this theme, namely, needs, nurture and building local communities with resilient children at their hearts.

Professor John Cox, Professor Emeritus of Psychiatry, talked about childbirth, adolescence and his Edinburgh Postnatal Depression Scale. Cohort Studies suggest that adolescence is a time of emotional turmoil particularly with the offspring of mothers with perinatal depression - and as a marker of future perinatal disorder. He illustrated that a little bit of empathy for a new mother may make a difference over a lifetime for a child.

The Thursday afternoon parallel sessions centered, among other topics, around a person centred integrative diagnostic model (never say ‘don’t worry', but 'there is a way we can help you with your worry'), a new patient centred approach to unlock and activate the individual's potential for better lives, the power of narratives (realities are created through stories and a consultation is a meeting of stories; look after ICE: Ideas, Concerns and Expectations) and the example of the burden of familial hypercholesterolemia.

During the closing session of the day, Jim Appleyard received several suggestions for topics to be included in the London Declaration which was distributed among all participants.

\section{Day 3: Saturday October 31st}

The last day of the conference started with three interesting lectures given by Professor Ted Epperly, Clinical Professor of Family Medicine at Washington University in Seattle, Anil Gayan, the foreign Minister of Mauritius, and Dr AbdulMajeed Salmasi, senior research fellow at the National Heart and Lung Institute and Director of Cardiovascular Teaching and Training at NHS Brent, UK. Ted Epperly talked about person centred family medicine being a foundation element to all health care systems around the world. Anil Gayan discussed challenges of planning and delivering healthcare in developing countries and Abdul-Majeed Salmasi reviewed integrated care for patients with atrial fibrillation and the need to promote awareness among patients about using medication to prevent strokes.

The morning parallel sessions focused on person centred topics like people powered health, community centred approaches to health and well-being, patient leadership, and patients as partners. An important outcome of the latter was the concept of co-production, i.e. the importance of delivering public services in an equal and reciprocal relationship among professionals, services and patients. Patient leadership is not a position or a title, but an action!

After lunch, Professor Marisa Papaluca, head of Section for Scientific Support and Projects in the Sector on Human Medicines Special Areas, and Professor Azeem Majeed, talked about personalized medicine and about research and innovation in primary care, respectively. The last parallel session covered several person centered medicine topics such as 
inter professional education and developing international person- and people-centered standards for medical curriculum evaluation and accreditation.

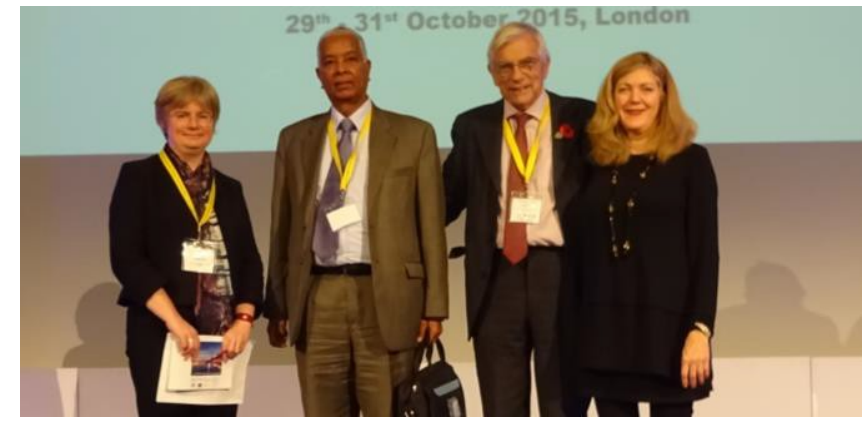

\section{Dr Rachel Matthews, Dr Tesfamichael Ghebrehiwet, Prof J im Appleyard, and Dr Susanna Mc Cune}

At the concluding session, Professor Jim Appleyard presented the final draft of the London Declaration and formally closed this inspiring event. This has shown us that there is still a lot more to do in the field of person centered (primary) care around the world, but, as seen from the many good and successful projects in all regions of the world presented at the Congress, progress is being made as lessons are being learnt by those who listen to and support the underlying message of the London Declaration. 